\title{
Posterior Subcapsular Cataract
}

National Cancer Institute

\section{Source}

National Cancer Institute. Posterior Subcapsular Cataract. NCI Thesaurus. Code

C135180.

A type of cataract that forms in the most posterior cortical layer of the lens, directly under the lens capsule. This type of cataract tends to occur in younger patients than cortical or nuclear sclerotic cataracts. 